Predicting Bond Betas using Macro-Finance Variables

Nektarios Aslanidis, Charlotte Christiansen and Andrea Cipollini

CREATES Research Paper 2017-1 


\title{
Predicting Bond Betas using Macro-Finance Variables*
}

\author{
Nektarios Aslanidis ${ }^{\dagger}$ \\ Universitat Rovira i Virgili, CREIP \\ Charlotte Christiansen ${ }^{\ddagger}$ \\ Andrea Cipollini ${ }^{\S}$ \\ CREATES, Aarhus University \\ University of Palermo
}

January 10, 2017

${ }^{*}$ Aslanidis acknowledges support from the Spanish Ministry of Science and Innovation project grant (Reference $\mathrm{N}^{\circ}$ ECO2013-42884-P). Christiansen acknowledges support from CREATES funded by the Danish National Research Foundation (DNRF78) and from the Danish Council for Independent Research, Social Sciences (DFF - 4003-00022).

${ }^{\dagger}$ Universitat Rovira i Virgili, Department d’Economia, CREIP, Avinguda Universitat 1, 43204 Reus, Spain. Email: nektarios.aslanidis@urv.cat.

${ }^{\ddagger}$ CREATES, Department of Economics and Business Economics, School of Business and Social Sciences, Aarhus University, Fuglesangs Allé 4, 8210 Aarhus V, Denmark and Lund University. Email: CChristiansen@econ.au.dk.

${ }^{\S}$ Department of Economics, Management and Statistics, University of Palermo, Viale delle Scienze, Palermo, Italy. Email: andrea.cipollini@unipa.it. 


\title{
Predicting Bond Betas using Macro-Finance Variables
}

\begin{abstract}
We conduct in-sample and out-of-sample forecasting using the new approach of combining explanatory variables through complete subset regressions (CSR). We predict bond CAPM betas and bond returns conditioning on various macro-finance variables. We explore differences across long-term government bonds, investment grade corporate bonds, and highyield corporate bonds. The CSR method performs well in predicting bond betas, especially in-sample, and, mainly high-yield bond betas when the focus is out-of-sample. Bond returns are less predictable than bond betas.
\end{abstract}

Keywords: bond betas; complete subset regressions; corporate bonds; macro-finance variables; model confidence set; risk-return trade-off.

JEL Classifications: C30; C53; G12. 


\section{Introduction}

Comovements between bond and equity markets are important for asset allocation, risk analysis, and hedging. This paper examines the in-sample and out-of-sample predictability of bond risk by means of macroeconomic and financial variables. We use a number of well-known predictors from the return predictability literature and explore differences across long-term government bonds, investment grade corporate bonds, and high-yield corporate bonds. Our results provide evidence that the combination of forecasts from complete subset regressions (CSR) as suggested by Elliott, Gargano, and Timmermann (2013) improves predictability of the bond betas relative to a benchmark model. Furthermore, we find large differences in forecast behavior across bond types, ranging from long-term government bonds over investment grade corporate bonds to high-yield corporate bonds. Furthermore, we investigate differences in predictability of bond betas and bond returns.

The present paper draws on a recent approach in the financial literature that uses information from large data sets of macro-finance variables to predict asset related variables (Baele, Bekaert, and Inghelbrecht (2010), Ludvigson and Ng (2009), Ludvigson and Ng (2010), and Aslanidis and Christiansen (2014), among others). More specifically, we adopt forecast combinations from CSR that uses financial variables from the literature on stock return predictability (the Goyal and Welch (2008) data set), in addition to macroeconomic predictors such as industrial production and the macroeconomic uncertainty index of Jurado, Ludvingson, and Ng (2015) along with an indicator of financial leverage and the liquidity factor of Pastor and Stambaugh (2003).

We measure bond risk by its CAPM beta, i.e. its covariance with the stock market divided by the stock variance. Beta is the normalized measure of the bond-stock covariance and it is readily available for interpretation as 
the CAPM risk. This measure of bond risk has been considered by previous studies such as Campbell, Sunderam, and Viceira (2013). Viceira (2012) studies the time variation in the government bond beta and shows that it is related to the yield spread and the short rate. Our contribution to Viceira (2012) is mainly to investigate if the term structure dependence of bond betas varies across bond type. Moreover, unlike Viceira (2012) we consider a large set of predictors.

The choice of the predictors used in this paper is foremost motivated by the literature that relates business cycle proxies to aggregate comovements in bond and equity markets. Some authors (see Campbell and Ammer (1993), Fama and French (1993), Boudoukh, Richardson, and Whitelaw (1994), and more recently Campbell, Sunderam, and Viceira (2013)) explore fundamental factors such as macro-drivers of interest rates (e.g. shocks to expected inflation and innovations to real interest rates), while others concentrate on non-fundamental determinants of the bond and stock return covariation. For example, Connolly, Stivers, and Sun (2007) show that the probability of having a negative bond-stock correlation increases with uncertainty (flight-to-safety). In a similar spirit, Baele, Bekaert, and Inghelbrecht (2010) show that macroeconomic fundamentals contribute little to explaining stock and bond return correlations while other factors, especially liquidity proxies, play a more important role. Further, Campbell, Pflueger, and Viceira (2015) make a New Keynesian general equilibrium model where changes in monetary policy contribute to shifts in bond risk.

The previous literature makes us expect that the behavior of bond betas differ across bond types. Recently, Choi, Richardson, and Whitelaw (2014) show that a firm's leverage is an important driver of the relation between its stock and bonds: the higher the leverage (measured by debt to asset ratio) is, the smaller is the degree of comovement. Moreover, other studies such as Bao, Hou, and Zhang (2015) and Bao and Hou (2016) stress the importance 
of firm capital structure to explain comovements between bond and equity. Bao, Hou, and Zhang (2015) use structural form credit risk models to show both theoretically and empirically the importance of a systemic default risk measure as a common factor driving the prices of stocks and corporate bonds.

Our empirical results are summarized as follows. Bond betas are predictable by the term structure of interest rates. Government and investment grade corporate bond betas depend positively on the term structure, whereas for high-yield corporate bond betas the dependence is negative. Based on the RMSEs, combining macro-finance variables via complete subset regressions is particularly advantageous for predicting bond betas in-sample whereas using single macro-finance variables is a competitive alternative for outof-sample bond beta predictions. Based upon RMSEs the bond returns are more difficult to predict than bond betas. The predictability is similar across bond types. When using the model confidence set of Hansen, Lunde, and Nason (2011) as a goodness-of-fit measure, our results suggest that the complete subset regressions provide good bond beta predictions out-of-sample. Still, the bond returns are difficult to predict also when judged by the model confidence approach. The qualitative results are similar for 3-month and 12month forecast horizons. The CSR results are also similar for stock industry portfolios and for corporate bond indices.

The remaining part of the paper is structured as follows. First, we introduce the data and then, we provide the econometric methodology. Subsequently, we discuss the empirical findings before we conclude. Various robustness results are delegated to the Appendix.

\section{Data}

We use monthly observations during the period $2000 M 05$ to $2014 M 12$. The start of the sample period is determined by the availability of the corporate bond data. 


\subsection{Realized CAPM Betas}

In order to calculate the monthly realized bond betas, we use daily observations of bond and stock returns. This is done the same way as Viceira (2012), namely as the realized stock-bond covariance divided by the realized stock variance.

For government bonds we apply the US benchmark 10-year DataStream government index, for investment grade corporate bonds we apply the Barclays US Corporate Investment Grade index, and for high-yield corporate bonds we apply the Barclays US Corporate High Yield index. For the stock market we use the S\&P 500 Composite Price Index. All bond and stock data are total return indices from DataStream.

Table 1 shows sample statistics for the monthly bond betas and bond returns for the full sample period. The average bond betas are decreasing with bond quality, i.e. for the government bond beta the mean is -0.127 , for the investment grade bond beta -0.062 and for the high-yield bond beta 0.054. Government and investment grade bonds appear to be on average safe investments that exhibit a negative correlation with aggregate wealth as proxied by the stock market, while the riskier high-yield bonds exhibit a positive correlation. The bond betas are slightly right skewed and the high-yield bond beta has a fat tail whereas the other bond betas are close to being mesokurtic. As for the bond returns, the Sharpe ratio of investment grade bonds is 0.36 , for government bonds it is lower at 0.26 and for highyield bonds it is even lower at 0.22 . The bonds returns are left skewed and all returns have fat tails. To examine the persistency in the data, Table 1 also reports the autocorrelation (at lag one) of the realized bond betas and bond returns. There is strong autocorrelation for bond betas and high-yield bond returns.

Figure 1 plots the realized bond betas (shaded areas are NBER recessions). In most of the sample, the high-yield bond beta is small and positive 
and shows little variation. Interestingly, the government and to a lesser extend the investment grade bond betas turn negative in 2008. This might be driven by "flight-to-quality" episodes during the recent financial crisis and subsequent great recession.

\author{
[Insert Table 1 here] \\ [Insert Figure 1 here]
}

\title{
2.2 Explanatory Variables
}

As explanatory variables we use macro-finance variables from Goyal and Welch (2008) combined with some newer and popular explanatory variables. The Goyal and Welch (2008) variables (available from Goyal's web page) include the dividend-price ratio $(D / P)$, the earnings-price ratio $(E / P)$, the book-to-market ratio $(B / M)$, the treasury bill rate $(T B L)$, the term spread $(T M S)$, the default return spread $(D F R)$, and inflation $(I N F L)$. Moreover, we use growth in industrial production (IP) (available from DataStream), the macroeconomic uncertainty index (uncertainty) of Jurado, Ludvingson, and $\mathrm{Ng}$ (2015) (available from Jurado's web page), the VIX volatility index $(V I X)$ (available from the web page of the Chicago Board of Options Exchange), along with a measure of financial leverage called the Chicago Fed National Financial Conditions Leverage Subindex (leverage) (available from the Federal Reserve Bank of St. Louis), and the liquidity factor (liquidity) of Pastor and Stambaugh (2003).

\section{$3 \quad$ Econometric Methodology}

The complete subset regression (CSR) methodology comes from Elliott, Gargano, and Timmermann (2013). CSR is a simple approach to deal with estimation error, model uncertainty, and model instability. By diversifying across multiple models, CSR can deliver more stable forecasts than those 
obtained from individual models. The method consists of using $k$ out of $K$ variables $(k \leq K)$ to fit linear regressions for all possible combinations of the $k$ variables. $K$ is the total number of predictors. The final forecast is the equally weighted average forecast computed from all regressions. Another advantage of the CSR is that it does not require any ranking of individual models. The forecasts are compared for all values of $k$. Each regression includes a constant and between 1 and $K$ regressors. In our setting there are 13 predictors (12 macro-finance variables plus the lagged dependent variable). There are in total $2^{13}=8,191$ different models. An exhaustive forecast combination of all possible models is no longer feasible.

For the out-of-sample analysis, we use the first six years of the sample (2000M05 - 2006M12) as warm-up to obtain initial estimates and the subsequent period (2007M01-2014M12) for out-of-sample forecast evaluation. All forecasts are generated recursively by OLS using an expanding estimation window. In the main analysis, we consider the 1-month horizon. In the Appendix we show the corresponding results for the 3-month and 12-month horizons.

We first compare model fit by computing the root mean square error (RMSE) for each of the forecasting models. Second, we follow Hansen, Lunde, and Nason (2011) and use the model confidence set (MCS) based on the RMSE as the loss function to compare model fit. The MCS test is a procedure that allows us to identify a subset of superior (prediction) models containing the best model(s) at a given level of confidence. We use a $75 \%$ confidence level.

\section{Empirical Results}

This section contains the empirical analysis. As preliminary analysis, we conduct similar analysis as Viceira (2012). Second, we investigate bond beta predictability, followed by bond return predictability. At last, we investigate 
differences between bond and stock betas.

\subsection{Effects of Term Structure of Interest Rates}

Similarly to Viceira (2012), we investigate if bond betas are predictable from the term structure of interest rates. For this reason, we regress the bond beta on the one-period lagged treasury bill rate $(T B L)$ and the one-period lagged term spread $(T M S)$. We include the one-period lagged bond beta to account for any autocorrelation. We also contribute to the literature by investigating how the term structure dependence of bond betas varies across bond types.

\section{[Insert Table 2]}

Table 2 shows the results from these regressions. Although the sample period in Viceira (2012) is different (1962 to 2007), our results for the government bond beta is very similar. The government bond beta depends positively and significantly on the treasury bill rate and positively but insignificantly on the term spread. The explanatory power is large with an adjusted $R$-squared of 0.25 . The explanatory power is not caused by including the lagged bond beta. When excluding the lagged bond beta, the adjusted $R$-squared is still as high as 0.17 .

The investment grade bond beta is also predictable by the term structure and there is also a positive dependence. The relation is weaker with an adjusted $R$-squared of 0.19 (dropping only to 0.12 when excluding the lagged bond beta).

The high-yield bond beta has negative and significant coefficients for the treasury bill rate and the term spread. So, the dependence for high-yield bonds has opposite sign from government and investment grade bonds.

Table 2 also shows that the bond returns are not strongly predictable by the term structure of interest rates (low $R$-squared values). The weaker 
predictability of first moments than second moments is in accordance with the stock market results in Ludvigson and Ng (2009) and Aslanidis, Christiansen, and Savva (2016).

So far, our findings indicate that investment grade bond behave similar to government bonds whereas high-yield bonds stand out.

\subsection{Predicting Bond Betas}

Table 3 shows the in-sample (left columns) and out-of-sample (right columns) RMSEs for each of the realized bond betas for 1-month ahead forecasting models. At the top, we show the RMSEs from the benchmark model (the $\operatorname{AR}(1)$ specification), followed by the RMSEs based on the CSR combination method for each possible $k$ and at the bottom are the RMSEs for the single-variable regressions.

\section{[Insert Table 3]}

In-sample, the results are qualitatively identical across bond quality. According to the RMSE, the CSR delivers more accurate predictions the larger the $k$ (the more variables are included in CSR). The CSR combinations are preferred to the benchmark AR (the RMSEs are reduced by about 1520\%). Importantly, all the CSR combinations have lower RMSEs than the single-variable regressions.

For the out-of-sample predictions, although most of the CSR combinations are better than the AR, the results vary qualitatively across bond quality. For example, for government and investment grade bond betas, single-predictor regressions now provide more accurate out-of-sample predictions compared to CSR. Interestingly, the best predictor for government and investment grade bond betas is the treasury bill rate $(T B L)$. This result supports Viceira (2012) and our results in Table 2. For the high-yield bond betas, there is not much difference across models with the most accurate 
predictability being achieved using individual predictors such as the treasury bill rate $(T B L)$ and the book-to-market ratio $(B / M)$, as well as CSR with $k=6,7,8$. Overall and regardless of the bond type, the CSR combinations delivering the lowest RMSE are associated with fewer variables than for in-sample predictions. Therefore, out-of-sample, many predictors appear to result in over-fitting.

Table 4 reports the selected variables based upon the model confidence set (MCS) approach for predicting bond betas both in-sample and out-ofsample. In-sample, none of the individual predictors are included in the MCS, which confirms the superior in-sample forecasting performance of CSR combinations relative to individual predictors regardless of the bond type.

Out-of-sample the picture is, however, different. For government and investment grade bond betas, the MCS includes only individuals predictors (e.g. the treasury bill rate $(T B L)$ and the book-to-market ratio $(B / M))$. This finding is in line with the results in Table 3 confirming the good outof-sample performance of those individual predictors relative to CSR. As for the high-yield bond beta and in terms of MCS, the CSR combinations with $k=5, \ldots, 11$ perform about as well as the $T B L$ and $B / M$ predictors.

\section{[Insert Table 4].}

\subsection{Predicting Bond Returns}

Table 5 shows the RMSEs for predicting bond returns in a manner similar to Table 3 for bond betas.

In-sample, the results are qualitatively similar to those for predicting bond betas. The CSR method delivers more accurate predictions the more variables are included (with the lowest RMSEs obtained when all 13 predictors are included).

Out-of-sample, single-variable predictions, as with bond betas, result in the lowest RMSEs. For example, for government and investment grade 
bonds the industrial production is the preferred macro-finance predictor. But for the high-yield bond, the benchmark AR delivers the lowest RMSE.

\section{[Insert Table 5]}

Table 6 shows the MCS results for predicting bond returns. In terms of the MCS approach, both in-sample and out-of-sample it is hard to distinguish between models as almost all specifications are included in the best model. Actually, the MCS confirms that the bond returns are difficult to predict. This finding is in line with the Viceira (2012) regressions in Table 2 above.

\section{[Insert Table 6]}

\subsection{Variations across Horizon}

The Appendix contains the RMSEs of the models for the 3-month and 12month horizon predictions. Qualitatively, the results tend to be similar to the 1-month horizon results.

Table $A 1$ shows the RMSEs for realized bond betas. As with the 1month horizon results, the CSR delivers more accurate predictions the more variables are included in CSR combinations. Across horizons and bond types, almost all CSR combinations have lower RMSEs than the singlevariable regressions.

However, out-of-sample, the best forecasts of government and investment grade bond betas are those related to individual variables while for the highyield bonds the best forecasts are CSR combinations.

Table $A 2$ shows the RMSEs for bond returns. While, in-sample, CSR predictions outperform individual predictors and the benchmark at the 3month and 12-month horizons, the reverse occurs when the focus is on outof-sample analysis. 


\subsection{Stock Industry Portfolios}

To investigate if our empirical results are specific to corporate bond betas, we analyze stock industry betas. We apply the Fama-French five industry portfolios available from Kenneth French's online data library; consumer, manufacturing, high tech, health care, and other. Tables $A 3-A 6$ in the Appendix show the 1-month horizon results.

The means and standard deviations for stock industry betas are much larger than for bond betas. The Viceira (2012) regressions show that the stock industry betas depend negatively on the term structure (except for health care). This is similar to the high-yield bond betas. So, the high-yield bond betas behavior is closer to stock industry portfolios than to government bonds.

The results for CSR are similar when applied to industry portfolio betas rather than bond betas. Although CSR outperforms in-sample individual variables and the benchmark, they perform poorly out-of-sample, since their predictions are not statistically different from the benchmark. Moreover, there is no difference between CSR, individuals and benchmark when the focus is on out-of-sample prediction of industry stock returns. Still, it could be the case that the CSR methodology would provide better results if it were used to individual asset betas.

\section{Conclusion}

In this paper we explore the role played by macro-finance variables for predicting bond betas and bond returns. We investigate three different categories of bonds, namely long-term government bonds, investment grade corporate bonds, and speculative grade corporate bonds. We make use of a new method for combining predictions from various explanatory variables, namely the complete subset regressions method. We find that the complete 
subset regression method performs well at predicting bond betas. Bond returns are less predictable. The differences across bond types are not so pronounced. The complete subset regression method appears to perform better for in-sample than out-of-sample predictions.

\section{References}

Aslanidis, N., and C. Christiansen (2014): "Quantiles of the Realized Stock-Bond Correlation," Journal of Empirical Finance, 28, 321-331.

Aslanidis, N., C. Christiansen, and C. S. Savva (2016): "Risk-return trade-off for European stock markets," International Review of Financial Analysis, 46, $84-103$.

Baele, L., G. Bekaert, and K. Inghelbrecht (2010): "The Determinants of Stock and Bond Return Comovements," Review of Financial Studies, 23(6).

Bao, J., and K. Hou (2016): "De Facto Seniority, Credit Risk, and Corporate Bond Prices," Working Paper.

Bao, J., K. Hou, and S. Zhang (2015): "Systemic Default and Return Predictability in the Stock and Bond Markets," Working Paper.

Boudoukh, J., M. Richardson, and R. F. Whitelaw (1994): "Industry Returns and the Fisher Effect," Journal of Finance, 49, 1595-1615.

Campbell, J. Y., And J. Ammer (1993): "What Moves the Stock and Bond markets? A Variance Decomposition for Long-Term Asset Returns," Journal of Finance, 48, 3-37.

Campbell, J. Y., C. Pflueger, and L. M. Viceira (2015): "Monetary Policy Drivers of Bond and Equity Risks," Working Paper. 
Campbell, J. Y., A. Sunderam, and L. M. Viceira (2013): "Inflation Bets or Deflation Hedges? The Changing Risks of Nominal Bonds," Working Paper.

Choi, J., M. P. Richardson, and R. Whitelaw (2014): "On the Fundamental Relation between Equity Returns and Interest Rates," Working Paper, SSRN.

Connolly, R. A., C. Stivers, and L. Sun (2007): "Commonality in the Time-Variation of Stock-Stock and Stock-Bond Return Comovements," Journal of Financial Markets, 10(2), 192-218.

Elliott, G., A. Gargano, and A. Timmermann (2013): "Complete Subset Regressions," Journal of Econometrics, 177, 357-373.

Fama, and French (1993): "Common Risk Factors in the Returns on Stocks and Bonds," Journal of Financial Economics, 33, 3-56.

Goyal, A., and I. Welch (2008): "A Comprehensive Look at The Empirical Performance of Equity Premium Prediction," The Review of Financial Studies, 21(4), 1455-1508.

Hansen, P., A. Lunde, and J. Nason (2011): "The Model Confidence Set," Econometrica, 79, 453-497.

Jurado, K., S. Ludvingson, And S. NG (2015): "Measuring Uncertainty," American Economic Review, 105(3), 1177-1216.

Ludvigson, S., And S. NG (2010): "A Factor Analysis of Bond Risk Premia," in Handbook of Empirical Economics and Finance, ed. by A. Uhla, and D. E. A. Giles, pp. 313-372. Chapman and Hall, Boca Raton, FL.

Ludvigson, S. C., And S. NG (2009): "Macro Factors in Bond Risk Premia," Review of Financial Studies, 22(2), 5027-5067. 
Pastor, L., and R. F. Stambaugh (2003): "Liquidity Risk and Expected Stock Returns," Journal of Political Economy, 111(3), 642-685.

Viceira, L. M. (2012): "Bond Risk, Bond Return Volatility, and the Term Structure of Interest Rates," International Journal of Forecasting, 28, 97117. 


\section{A Appendix: Longer Forecasting Horizons}

Here we show the results from analyzing corporate bonds at the 3-month and 12-month horizon.

[Insert Tables A1 and A2]

\section{B Appendix: Industry Portfolios}

Here we show the results from analyzing the 5-industry stock portfolios.

[Insert Tables A3-A6] 
Figure 1 Realized Bond Betas

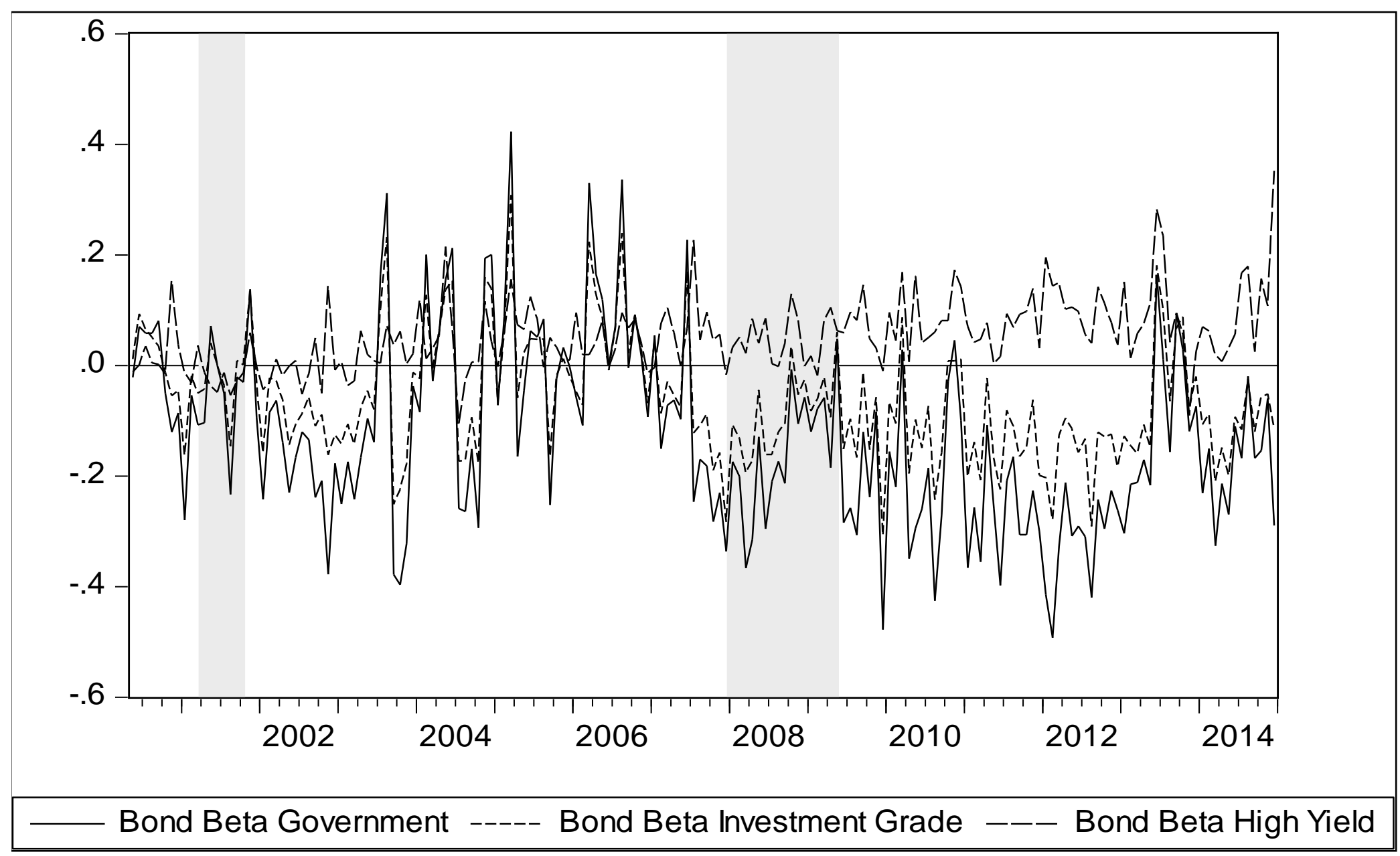

The figure shows the time series of the bond betas. The grey-shaded areas are the NBER recession periods. 
Table 1: Descriptive Statistics

\begin{tabular}{llrrrrr} 
& & Mean & St.Dev. & Skew. & Kurt. & Autocor(1) \\
\hline Betas & GOV & -0.1265 & 0.169 & 0.54 & 3.20 & 0.45 \\
& IG & -0.0623 & 0.110 & 0.60 & 3.43 & 0.38 \\
\multirow{3}{*}{ Returns } & HY & 0.0536 & 0.067 & 0.99 & 5.22 & 0.32 \\
& GOV & 0.0056 & 0.022 & -0.22 & 4.26 & 0.04 \\
& IG & 0.0060 & 0.017 & -1.17 & 8.66 & 0.22 \\
& HY & 0.0065 & 0.030 & -1.19 & 10.77 & 0.33 \\
\hline
\end{tabular}


Table 2: Viceira Regressions for Bonds

\begin{tabular}{|c|c|c|c|c|}
\hline & & GOV & IG & $\mathrm{HY}$ \\
\hline \multirow[t]{5}{*}{ Betas } & Constant & $-0.20 * * *$ & $-0.12 * * *$ & $0.16 * * *$ \\
\hline & Lagged & $0.33 * * *$ & $0.28 * * *$ & $0.19 * *$ \\
\hline & TBL & $3.56 * * *$ & $2.21 * * *$ & $-2.51 * * *$ \\
\hline & TMS & 1.97 & 1.33 & $-2.78 * * *$ \\
\hline & Adj. R-squared & 0.25 & 0.19 & 0.22 \\
\hline \multirow[t]{5}{*}{ Returns } & Constant & $-0.01 *$ & -0.01 & $0.01 *$ \\
\hline & Lagged & 0.06 & $0.23 * * *$ & $0.32 * * *$ \\
\hline & TBL & $0.39 * * *$ & $0.19 *$ & -0.26 \\
\hline & TMS & $0.48 * *$ & $0.29 * *$ & -0.20 \\
\hline & Adj. R-squared & 0.02 & 0.05 & 0.10 \\
\hline
\end{tabular}


Table 3: RMSEs for Bond Betas

\begin{tabular}{|c|c|c|c|c|c|c|}
\hline & \multicolumn{3}{|c|}{$\gg>$ In-Sample $\ll<<$} & \multicolumn{3}{|c|}{ >>> Out-of-Sample $\ll<<$} \\
\hline & GOV & IG & HY & GOV & IG & $\mathrm{HY}$ \\
\hline AR & 0.158 & 0.107 & 0.073 & 0.143 & 0.099 & 0.070 \\
\hline CSR, $k=1$ & 0.145 & 0.097 & 0.069 & 0.161 & 0.106 & 0.073 \\
\hline $\mathrm{CSR}, \mathrm{k}=2$ & 0.140 & 0.095 & 0.067 & 0.157 & 0.104 & 0.072 \\
\hline $\operatorname{CSR}, k=3$ & 0.137 & 0.094 & 0.066 & 0.155 & 0.104 & 0.070 \\
\hline $\mathrm{CSR}, \mathrm{k}=4$ & 0.135 & 0.093 & 0.065 & 0.154 & 0.103 & 0.069 \\
\hline CSR, $k=5$ & 0.133 & 0.092 & 0.065 & 0.153 & 0.104 & 0.069 \\
\hline $\operatorname{CSR}, \mathrm{k}=6$ & 0.132 & 0.091 & 0.064 & 0.153 & 0.104 & 0.068 \\
\hline CSR, $k=7$ & 0.131 & 0.091 & 0.064 & 0.154 & 0.104 & 0.068 \\
\hline CSR, $k=8$ & 0.130 & 0.090 & 0.064 & 0.154 & 0.105 & 0.068 \\
\hline CSR, $k=9$ & 0.129 & 0.090 & 0.064 & 0.155 & 0.105 & 0.069 \\
\hline CSR, $k=10$ & 0.128 & 0.089 & 0.064 & 0.156 & 0.106 & 0.069 \\
\hline $\mathrm{CSR}, \mathrm{k}=11$ & 0.127 & 0.089 & 0.063 & 0.158 & 0.107 & 0.069 \\
\hline CSR, $\mathrm{k}=12$ & 0.126 & 0.088 & 0.063 & 0.160 & 0.109 & 0.070 \\
\hline CSR, $k=13$ & 0.126 & 0.088 & 0.063 & 0.163 & 0.110 & 0.070 \\
\hline$D / P$ & 0.154 & 0.105 & 0.071 & 0.140 & 0.097 & 0.069 \\
\hline$E / P$ & 0.158 & 0.107 & 0.073 & 0.149 & 0.102 & 0.072 \\
\hline$B / M$ & 0.154 & 0.104 & 0.071 & 0.140 & 0.097 & 0.068 \\
\hline TBL & 0.159 & 0.107 & 0.071 & 0.136 & 0.095 & 0.068 \\
\hline TMS & 0.158 & 0.107 & 0.072 & 0.143 & 0.099 & 0.070 \\
\hline DFR & 0.158 & 0.107 & 0.073 & 0.146 & 0.101 & 0.071 \\
\hline INFL & 0.158 & 0.107 & 0.073 & 0.143 & 0.099 & 0.070 \\
\hline IP & 0.158 & 0.107 & 0.073 & 0.147 & 0.101 & 0.071 \\
\hline VIX & 0.159 & 0.107 & 0.073 & 0.144 & 0.100 & 0.071 \\
\hline leverage & 0.158 & 0.107 & 0.073 & 0.144 & 0.099 & 0.070 \\
\hline uncertainty & 0.158 & 0.106 & 0.073 & 0.149 & 0.101 & 0.071 \\
\hline liquidity & 0.157 & 0.106 & 0.072 & 0.145 & 0.100 & 0.072 \\
\hline
\end{tabular}


Table 4: MCS Results for Bond Betas (at 75\% level)

>> In-Sample $<<<\quad \quad$ >> Out-of-Sample $<<<$

\begin{tabular}{|c|c|c|c|c|c|c|}
\hline & GOV & IG & $\mathrm{HY}$ & GOV & IG & HY \\
\hline \multicolumn{7}{|l|}{ AR } \\
\hline \multicolumn{7}{|l|}{ CSR, $k=1$} \\
\hline \multicolumn{7}{|l|}{ CSR, $k=2$} \\
\hline CSR, $k=3$ & Yes & & & & & \\
\hline $\mathrm{CSR}, \mathrm{k}=4$ & Yes & & & & & \\
\hline$C S R, k=5$ & Yes & & & & & Yes \\
\hline $\mathrm{CSR}, \mathrm{k}=6$ & Yes & & & & & Yes \\
\hline CSR, $k=7$ & Yes & & Yes & & & Yes \\
\hline CSR, $k=8$ & Yes & & Yes & & & Yes \\
\hline CSR, $k=9$ & Yes & & Yes & & & Yes \\
\hline CSR, $k=10$ & Yes & & Yes & & & Yes \\
\hline CSR, $k=11$ & Yes & & Yes & & & Yes \\
\hline CSR, $k=12$ & Yes & & Yes & & & \\
\hline CSR, $k=13$ & Yes & Yes & Yes & & & \\
\hline$D / P$ & & & & Yes & Yes & Yes \\
\hline \multicolumn{7}{|l|}{$E / P$} \\
\hline $\mathrm{B} / \mathrm{M}$ & & & & Yes & Yes & Yes \\
\hline TBL & & & & Yes & Yes & Yes \\
\hline TMS & & & & Yes & Yes & \\
\hline \multicolumn{7}{|l|}{ DFR } \\
\hline \multicolumn{7}{|l|}{ INFL } \\
\hline \multicolumn{7}{|l|}{ IP } \\
\hline \multicolumn{7}{|l|}{ VIX } \\
\hline \multicolumn{7}{|l|}{ leverage } \\
\hline \multicolumn{7}{|l|}{ uncertainty } \\
\hline liquidity & & & & & & \\
\hline
\end{tabular}


Table 5: RMSEs for Bond Returns

\begin{tabular}{|c|c|c|c|c|c|c|}
\hline & \multicolumn{3}{|c|}{ 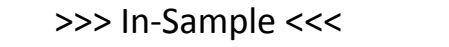 } & \multicolumn{3}{|c|}{ 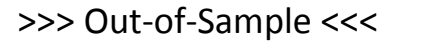 } \\
\hline & GOV & IG & $\mathrm{HY}$ & GOV & IG & $\mathrm{HY}$ \\
\hline AR & 2.207 & 1.890 & 3.507 & 2.235 & 1.848 & 3.214 \\
\hline CSR, $k=1$ & 2.190 & 1.803 & 3.266 & 2.239 & 1.850 & 3.367 \\
\hline CSR, $k=2$ & 2.162 & 1.762 & 3.182 & 2.251 & 1.849 & 3.374 \\
\hline $\operatorname{CSR}, \mathrm{k}=3$ & 2.130 & 1.724 & 3.102 & 2.258 & 1.852 & 3.387 \\
\hline CSR, $k=4$ & 2.095 & 1.688 & 3.026 & 2.259 & 1.856 & 3.401 \\
\hline CSR, $k=5$ & 2.058 & 1.656 & 2.955 & 2.254 & 1.861 & 3.412 \\
\hline CSR, $k=6$ & 2.022 & 1.626 & 2.889 & 2.244 & 1.867 & 3.422 \\
\hline $\operatorname{CSR}, \mathrm{k}=7$ & 1.988 & 1.600 & 2.830 & 2.233 & 1.876 & 3.431 \\
\hline CSR, $k=8$ & 1.959 & 1.577 & 2.779 & 2.227 & 1.889 & 3.444 \\
\hline CSR, $k=9$ & 1.936 & 1.558 & 2.735 & 2.231 & 1.908 & 3.461 \\
\hline CSR, $k=10$ & 1.918 & 1.542 & 2.698 & 2.248 & 1.934 & 3.485 \\
\hline CSR, $\mathrm{k}=11$ & 1.905 & 1.529 & 2.669 & 2.285 & 1.971 & 3.519 \\
\hline CSR, $k=12$ & 1.897 & 1.520 & 2.646 & 2.345 & 2.018 & 3.561 \\
\hline CSR, $k=13$ & 1.892 & 1.514 & 2.629 & 2.432 & 2.077 & 3.615 \\
\hline$D / P$ & 2.209 & 1.886 & 3.462 & 2.282 & 1.897 & 3.261 \\
\hline$E / P$ & 2.229 & 1.869 & 3.499 & 2.264 & 1.834 & 3.231 \\
\hline $\mathrm{B} / \mathrm{M}$ & 2.207 & 1.889 & 3.513 & 2.252 & 1.859 & 3.233 \\
\hline TBL & 2.202 & 1.890 & 3.469 & 2.248 & 1.865 & 3.229 \\
\hline TMS & 2.208 & 1.872 & 3.480 & 2.242 & 1.846 & 3.220 \\
\hline DFR & 2.203 & 1.908 & 3.507 & 2.273 & 1.865 & 3.442 \\
\hline INFL & 2.216 & 1.901 & 3.496 & 2.267 & 1.878 & 3.257 \\
\hline IP & 2.235 & 1.956 & 3.588 & 2.167 & 1.828 & 3.337 \\
\hline VIX & 2.206 & 1.876 & 3.500 & 2.330 & 1.971 & 3.394 \\
\hline leverage & 2.205 & 1.893 & 3.535 & 2.255 & 1.866 & 3.243 \\
\hline uncertainty & 2.226 & 1.882 & 3.460 & 2.284 & 1.863 & 3.227 \\
\hline liquidity & 2.212 & 1.894 & 3.505 & 2.289 & 1.896 & 3.311 \\
\hline
\end{tabular}


Table 6: MCS Results for Bond Returns (at 75\% level)

\begin{tabular}{|c|c|c|c|c|c|c|}
\hline & \multicolumn{3}{|c|}{$\gg>$ In-Sample $\ll<<$} & \multicolumn{3}{|c|}{ >>> Out-of-Sample $\ll<<$} \\
\hline & GOV & IG & $\mathrm{HY}$ & GOV & IG & HY \\
\hline$A R$ & Yes & Yes & Yes & Yes & Yes & Yes \\
\hline $\mathrm{CSR}, \mathrm{k}=1$ & Yes & Yes & Yes & Yes & Yes & Yes \\
\hline CSR, $k=2$ & Yes & Yes & Yes & Yes & Yes & Yes \\
\hline CSR, $k=3$ & Yes & Yes & Yes & Yes & Yes & Yes \\
\hline CSR, $k=4$ & Yes & Yes & Yes & Yes & Yes & Yes \\
\hline CSR, $k=5$ & Yes & Yes & Yes & Yes & Yes & Yes \\
\hline CSR, $k=6$ & Yes & Yes & Yes & Yes & Yes & Yes \\
\hline CSR, $k=7$ & Yes & Yes & Yes & Yes & Yes & Yes \\
\hline $\mathrm{CSR}, \mathrm{k}=8$ & Yes & Yes & Yes & Yes & Yes & Yes \\
\hline CSR, $k=9$ & Yes & Yes & Yes & Yes & Yes & Yes \\
\hline CSR, $k=10$ & Yes & Yes & Yes & Yes & Yes & Yes \\
\hline CSR, $k=11$ & Yes & Yes & Yes & Yes & & Yes \\
\hline CSR, $k=12$ & Yes & Yes & Yes & Yes & & \\
\hline CSR, $k=13$ & Yes & Yes & Yes & Yes & & \\
\hline$D / P$ & Yes & Yes & & Yes & Yes & Yes \\
\hline$E / P$ & Yes & Yes & Yes & Yes & Yes & Yes \\
\hline $\mathrm{B} / \mathrm{M}$ & Yes & Yes & & Yes & Yes & Yes \\
\hline TBL & Yes & Yes & Yes & Yes & Yes & Yes \\
\hline TMS & Yes & Yes & Yes & Yes & Yes & Yes \\
\hline DFR & Yes & Yes & Yes & Yes & Yes & Yes \\
\hline INFL & Yes & Yes & Yes & Yes & Yes & Yes \\
\hline IP & Yes & & Yes & Yes & Yes & Yes \\
\hline VIX & Yes & Yes & Yes & Yes & Yes & Yes \\
\hline leverage & Yes & & & Yes & Yes & Yes \\
\hline uncertainty & Yes & Yes & Yes & Yes & Yes & Yes \\
\hline liquidity & Yes & Yes & Yes & Yes & Yes & Yes \\
\hline
\end{tabular}


Table A1: RMSEs for Bond Betas for Longer Horizons

>>> Horizon 3-Month $<<<$

\begin{tabular}{|c|c|c|c|c|c|c|}
\hline & $\gg>$ & ample & & $\gg>0$ & f-Samp & \\
\hline & GOV & IG & $\mathrm{HY}$ & GOV & IG & $\mathrm{HY}$ \\
\hline$A R$ & 0.151 & 0.101 & 0.070 & 0.154 & 0.104 & 0.075 \\
\hline$C S R, k=1$ & 0.144 & 0.097 & 0.069 & 0.164 & 0.107 & 0.074 \\
\hline CSR, $k=2$ & 0.141 & 0.095 & 0.067 & 0.162 & 0.107 & 0.073 \\
\hline CSR, $k=3$ & 0.138 & 0.094 & 0.066 & 0.162 & 0.107 & 0.072 \\
\hline $\operatorname{CSR}, \mathrm{k}=4$ & 0.136 & 0.094 & 0.065 & 0.163 & 0.108 & 0.071 \\
\hline CSR, $k=5$ & 0.134 & 0.093 & 0.065 & 0.164 & 0.109 & 0.070 \\
\hline CSR, $k=6$ & 0.133 & 0.092 & 0.064 & 0.166 & 0.111 & 0.070 \\
\hline CSR, $k=7$ & 0.131 & 0.091 & 0.063 & 0.169 & 0.113 & 0.069 \\
\hline $\operatorname{CSR}, \mathrm{k}=8$ & 0.130 & 0.090 & 0.063 & 0.171 & 0.114 & 0.069 \\
\hline CSR, $k=9$ & 0.129 & 0.090 & 0.063 & 0.174 & 0.117 & 0.070 \\
\hline CSR, $k=10$ & 0.128 & 0.089 & 0.062 & 0.178 & 0.119 & 0.070 \\
\hline CSR, $k=11$ & 0.127 & 0.089 & 0.062 & 0.183 & 0.123 & 0.071 \\
\hline CSR, $k=12$ & 0.127 & 0.088 & 0.062 & 0.189 & 0.127 & 0.073 \\
\hline CSR, $k=13$ & 0.127 & 0.088 & 0.062 & 0.197 & 0.131 & 0.075 \\
\hline$D / P$ & 0.147 & 0.099 & 0.070 & 0.152 & 0.104 & 0.072 \\
\hline$E / P$ & 0.151 & 0.101 & 0.071 & 0.169 & 0.113 & 0.079 \\
\hline $\mathrm{B} / \mathrm{M}$ & 0.147 & 0.098 & 0.069 & 0.155 & 0.105 & 0.069 \\
\hline TBL & 0.151 & 0.101 & 0.068 & 0.147 & 0.101 & 0.072 \\
\hline TMS & 0.150 & 0.101 & 0.070 & 0.156 & 0.106 & 0.075 \\
\hline DFR & 0.150 & 0.101 & 0.070 & 0.155 & 0.106 & 0.076 \\
\hline INFL & 0.151 & 0.101 & 0.071 & 0.155 & 0.105 & 0.075 \\
\hline IP & 0.151 & 0.101 & 0.071 & 0.154 & 0.104 & 0.076 \\
\hline VIX & 0.151 & 0.101 & 0.070 & 0.157 & 0.106 & 0.077 \\
\hline leverage & 0.151 & 0.101 & 0.070 & 0.154 & 0.105 & 0.075 \\
\hline uncertainty & 0.151 & 0.101 & 0.071 & 0.166 & 0.110 & 0.077 \\
\hline liquidity & 0.150 & 0.100 & 0.070 & 0.161 & 0.108 & 0.078 \\
\hline
\end{tabular}


>> Horizon 12-Month $<<<$

\begin{tabular}{|c|c|c|c|c|c|c|}
\hline & $\gg>$ & iample $<$ & & $\gg \gg 0$ & f-Samp & \\
\hline & GOV & IG & HY & GOV & IG & HY \\
\hline$A R$ & 0.147 & 0.098 & 0.070 & 0.169 & 0.111 & 0.074 \\
\hline $\operatorname{CSR}, \mathrm{k}=1$ & 0.145 & 0.097 & 0.068 & 0.177 & 0.114 & 0.074 \\
\hline $\operatorname{CSR}, \mathrm{k}=2$ & 0.143 & 0.096 & 0.067 & 0.183 & 0.118 & 0.072 \\
\hline CSR, $k=3$ & 0.142 & 0.096 & 0.066 & 0.190 & 0.122 & 0.071 \\
\hline CSR, $k=4$ & 0.142 & 0.096 & 0.066 & 0.196 & 0.127 & 0.070 \\
\hline $\operatorname{CSR}, \mathrm{k}=5$ & 0.141 & 0.096 & 0.065 & 0.203 & 0.131 & 0.069 \\
\hline CSR, $\mathrm{k}=6$ & 0.141 & 0.096 & 0.065 & 0.210 & 0.134 & 0.069 \\
\hline $\operatorname{CSR}, \mathrm{k}=7$ & 0.140 & 0.095 & 0.064 & 0.217 & 0.138 & 0.069 \\
\hline $\operatorname{CSR}, \mathrm{k}=8$ & 0.140 & 0.095 & 0.064 & 0.225 & 0.143 & 0.070 \\
\hline CSR, $k=9$ & 0.140 & 0.095 & 0.064 & 0.234 & 0.148 & 0.071 \\
\hline CSR, $k=10$ & 0.140 & 0.095 & 0.064 & 0.245 & 0.155 & 0.073 \\
\hline CSR, k=11 & 0.140 & 0.095 & 0.063 & 0.259 & 0.163 & 0.075 \\
\hline $\mathrm{CSR}, \mathrm{k}=12$ & 0.140 & 0.096 & 0.063 & 0.276 & 0.174 & 0.078 \\
\hline CSR, $k=13$ & 0.141 & 0.096 & 0.063 & 0.297 & 0.189 & 0.082 \\
\hline $\mathrm{D} / \mathrm{P}$ & 0.143 & 0.097 & 0.070 & 0.185 & 0.119 & 0.074 \\
\hline$E / P$ & 0.148 & 0.099 & 0.070 & 0.201 & 0.129 & 0.082 \\
\hline$B / M$ & 0.144 & 0.096 & 0.069 & 0.190 & 0.122 & 0.071 \\
\hline TBL & 0.145 & 0.098 & 0.067 & 0.177 & 0.115 & 0.072 \\
\hline TMS & 0.145 & 0.098 & 0.069 & 0.177 & 0.117 & 0.076 \\
\hline DFR & 0.146 & 0.099 & 0.070 & 0.181 & 0.118 & 0.075 \\
\hline INFL & 0.147 & 0.098 & 0.070 & 0.168 & 0.110 & 0.075 \\
\hline IP & 0.147 & 0.098 & 0.069 & 0.173 & 0.112 & 0.076 \\
\hline VIX & 0.147 & 0.099 & 0.070 & 0.179 & 0.115 & 0.086 \\
\hline leverage & 0.147 & 0.098 & 0.070 & 0.171 & 0.111 & 0.075 \\
\hline uncertainty & 0.147 & 0.098 & 0.070 & 0.174 & 0.114 & 0.077 \\
\hline liquidity & 0.146 & 0.098 & 0.070 & 0.203 & 0.127 & 0.074 \\
\hline
\end{tabular}


Table A2: RMSEs for Bond Returns for Longer Horizons

>>> Horizon 3-Month $<<<$

\begin{tabular}{|c|c|c|c|c|c|c|}
\hline & \multicolumn{3}{|c|}{ »> In-Sample $\ll<<$} & \multicolumn{3}{|c|}{ 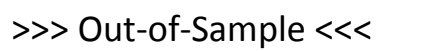 } \\
\hline & GOV & IG & $\mathrm{HY}$ & GOV & IG & $\mathrm{HY}$ \\
\hline$A R$ & 2.205 & 1.844 & 3.363 & 2.210 & 1.898 & 3.440 \\
\hline CSR, k=1 & 2.195 & 1.822 & 3.272 & 2.225 & 1.871 & 3.382 \\
\hline $\operatorname{CSR}, \mathrm{k}=2$ & 2.178 & 1.805 & 3.211 & 2.236 & 1.898 & 3.404 \\
\hline CSR, $k=3$ & 2.161 & 1.790 & 3.162 & 2.254 & 1.933 & 3.446 \\
\hline $\operatorname{CSR}, \mathrm{k}=4$ & 2.144 & 1.777 & 3.118 & 2.278 & 1.976 & 3.503 \\
\hline CSR, $k=5$ & 2.127 & 1.763 & 3.074 & 2.308 & 2.025 & 3.571 \\
\hline CSR, $k=6$ & 2.110 & 1.749 & 3.031 & 2.345 & 2.076 & 3.647 \\
\hline CSR, $k=7$ & 2.093 & 1.735 & 2.989 & 2.388 & 2.128 & 3.729 \\
\hline $\operatorname{CSR}, \mathrm{k}=8$ & 2.076 & 1.722 & 2.949 & 2.436 & 2.181 & 3.816 \\
\hline $\operatorname{CSR}, k=9$ & 2.061 & 1.710 & 2.912 & 2.490 & 2.235 & 3.906 \\
\hline $\mathrm{CSR}, \mathrm{k}=10$ & 2.046 & 1.699 & 2.880 & 2.551 & 2.289 & 3.997 \\
\hline CSR, $k=11$ & 2.033 & 1.690 & 2.852 & 2.619 & 2.345 & 4.088 \\
\hline CSR, $k=12$ & 2.021 & 1.683 & 2.829 & 2.698 & 2.401 & 4.178 \\
\hline CSR, $k=13$ & 2.011 & 1.678 & 2.811 & 2.789 & 2.457 & 4.267 \\
\hline $\mathrm{D} / \mathrm{P}$ & 2.219 & 1.836 & 3.322 & 2.185 & 2.007 & 3.546 \\
\hline$E / P$ & 2.209 & 1.821 & 3.345 & 2.240 & 1.871 & 3.518 \\
\hline$B / M$ & 2.215 & 1.844 & 3.401 & 2.204 & 1.914 & 3.418 \\
\hline TBL & 2.199 & 1.842 & 3.313 & 2.214 & 1.922 & 3.446 \\
\hline TMS & 2.205 & 1.826 & 3.301 & 2.216 & 1.903 & 3.430 \\
\hline DFR & 2.206 & 1.844 & 3.361 & 2.245 & 1.967 & 3.461 \\
\hline INFL & 2.182 & 1.846 & 3.356 & 2.215 & 1.974 & 3.400 \\
\hline IP & 2.213 & 1.844 & 3.321 & 2.361 & 1.935 & 3.435 \\
\hline VIX & 2.212 & 1.811 & 3.292 & 2.253 & 2.110 & 4.185 \\
\hline leverage & 2.210 & 1.852 & 3.364 & 2.215 & 1.909 & 3.450 \\
\hline uncertainty & 2.221 & 1.841 & 3.374 & 2.202 & 1.874 & 3.199 \\
\hline liquidity & 2.203 & 1.845 & 3.338 & 2.230 & 1.959 & 3.671 \\
\hline
\end{tabular}


>> Horizon 12-Month $<<<$

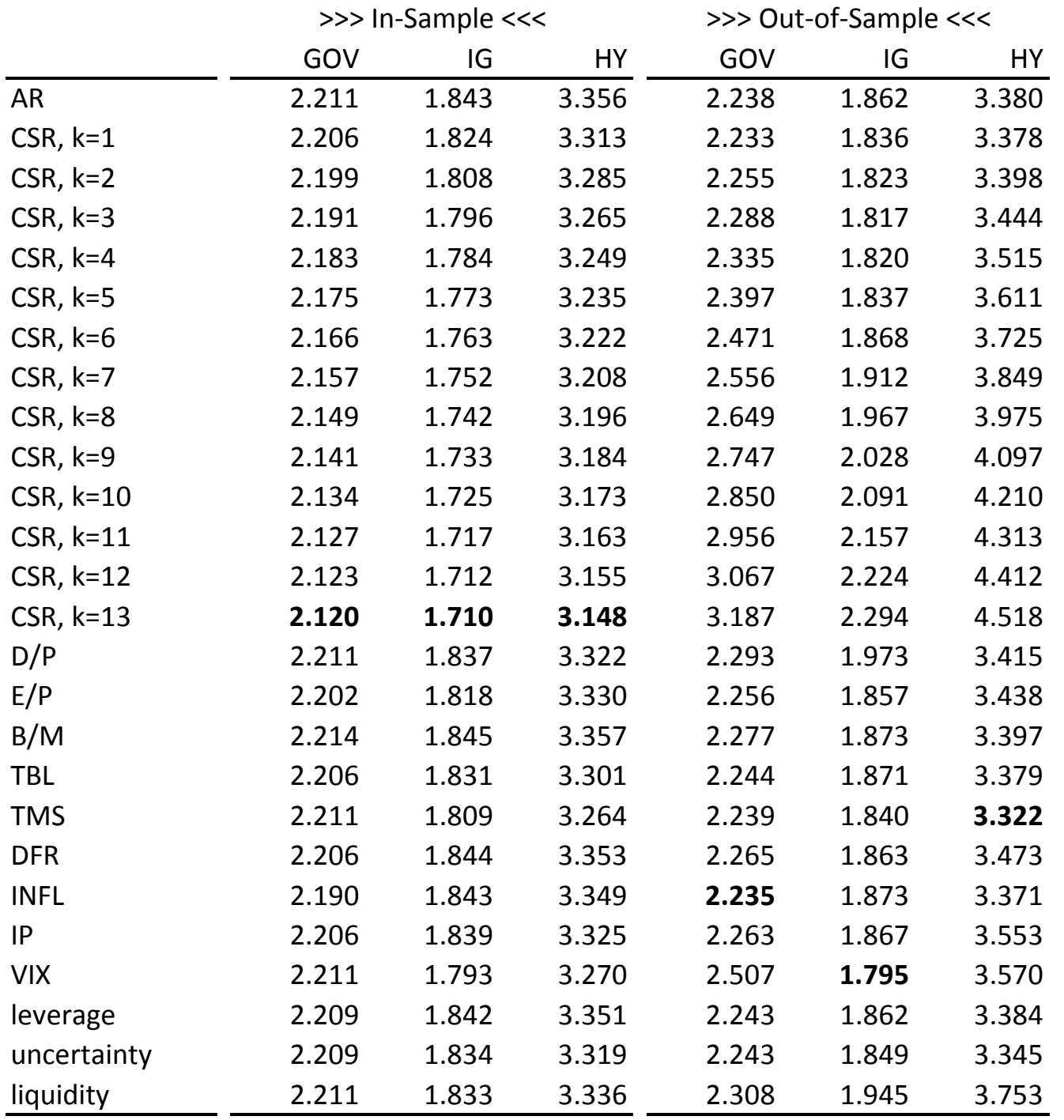


Table A3: Descriptive Statistics for Stocks

\begin{tabular}{llrrrrr} 
& & Mean & St.Dev. & Skew. & Kurt. & Autocor. \\
\hline Betas & CON & 0.809 & 0.16 & -1.01 & 5.68 & 0.65 \\
& MAN & 0.927 & 0.23 & -0.97 & 4.46 & 0.71 \\
& HT & 1.173 & 0.30 & 1.34 & 4.12 & 0.83 \\
& HEL & 0.751 & 0.24 & -0.88 & 6.06 & 0.55 \\
& OTH & 1.089 & 0.21 & 0.97 & 5.87 & 0.68 \\
Returns & CON & 0.881 & 3.74 & -0.79 & 4.67 & 0.12 \\
& MAN & 1.051 & 4.63 & -0.87 & 4.54 & 0.02 \\
& HT & 0.301 & 6.68 & -0.69 & 4.27 & 0.06 \\
& HE & 0.734 & 3.95 & -0.32 & 3.43 & 0.03 \\
& OT & 0.786 & 5.21 & -0.47 & 5.25 & 0.16 \\
\hline
\end{tabular}


Table A4: Viceira Regressions for Stocks

\begin{tabular}{|c|c|c|c|c|c|c|}
\hline & & CON & MAN & $\mathrm{HT}$ & HEL & OTH \\
\hline \multirow[t]{5}{*}{ Betas } & Constant & $0.35 * * *$ & $0.51 * * *$ & $0.12 * *$ & $0.47^{* * *}$ & $0.57^{* * *}$ \\
\hline & Lagged & $0.63 * * *$ & $0.63 * * *$ & $0.72 * * *$ & $0.49 * * *$ & $0.59 * * *$ \\
\hline & TBL & -1.06 & $-3.98 * * *$ & $4.80 * * *$ & $-2.99 *$ & $-3.24 * * *$ \\
\hline & TMS & -0.93 & $-3.73 * * *$ & $4.54 * *$ & -1.17 & $-2.41 * *$ \\
\hline & Adj. R-squared & 0.44 & 0.53 & 0.72 & 0.33 & 0.49 \\
\hline \multirow[t]{5}{*}{ Returns } & Constant & $4.05 * * *$ & $3.45^{* *}$ & $6.96 * * *$ & $5.90 * * *$ & $4.50^{* * *}$ \\
\hline & Lagged & 0.10 & 0.01 & 0.02 & -0.03 & $0.15 *$ \\
\hline & TBL & $-64.11 * * *$ & -42.30 & $-146.64 * * *$ & $-101.56 * * *$ & $-76.87 * * *$ \\
\hline & TMS & $-80.75 * *$ & -63.65 & $-153.93 * *$ & $-128.81 * * *$ & $-95.37 * * *$ \\
\hline & Adj. R-squared & 0.03 & -0.01 & 0.04 & 0.05 & 0.03 \\
\hline
\end{tabular}


Table A5: RMSEs for Stock Betas

\begin{tabular}{|c|c|c|c|c|c|c|c|c|c|c|}
\hline & CON & MAN & $\mathrm{HT}$ & HEL & OTH & CON & MAN & $\mathrm{HT}$ & HEL & $\mathrm{OTH}$ \\
\hline AR & 0.115 & 0.177 & 0.138 & 0.179 & 0.221 & 0.097 & 0.113 & 0.102 & 0.157 & 0.171 \\
\hline CSR, $k=1$ & 0.093 & 0.145 & 0.159 & 0.173 & 0.184 & 0.093 & 0.162 & 0.214 & 0.180 & 0.214 \\
\hline CSR, $k=2$ & 0.090 & 0.137 & 0.135 & 0.159 & 0.163 & 0.092 & 0.147 & 0.169 & 0.166 & 0.189 \\
\hline CSR, $k=3$ & 0.089 & 0.132 & 0.120 & 0.151 & 0.151 & 0.095 & 0.140 & 0.139 & 0.158 & 0.174 \\
\hline CSR, $k=4$ & 0.089 & 0.128 & 0.111 & 0.146 & 0.143 & 0.100 & 0.137 & 0.122 & 0.155 & 0.165 \\
\hline CSR, $k=5$ & 0.088 & 0.126 & 0.105 & 0.144 & 0.139 & 0.105 & 0.138 & 0.114 & 0.155 & 0.161 \\
\hline CSR, $k=6$ & 0.088 & 0.124 & 0.101 & 0.143 & 0.136 & 0.109 & 0.139 & 0.110 & 0.156 & 0.161 \\
\hline CSR, $k=7$ & 0.087 & 0.122 & 0.098 & 0.142 & 0.134 & 0.111 & 0.140 & 0.109 & 0.159 & 0.162 \\
\hline $\mathrm{CSR}, \mathrm{k}=8$ & 0.086 & 0.120 & 0.095 & 0.141 & 0.133 & 0.113 & 0.142 & 0.109 & 0.162 & 0.165 \\
\hline CSR, $k=9$ & 0.085 & 0.118 & 0.093 & 0.140 & 0.132 & 0.114 & 0.144 & 0.109 & 0.166 & 0.168 \\
\hline CSR, $k=10$ & 0.085 & 0.117 & 0.092 & 0.139 & 0.131 & 0.115 & 0.147 & 0.111 & 0.171 & 0.172 \\
\hline CSR, $k=11$ & 0.084 & 0.116 & 0.091 & 0.138 & 0.130 & 0.116 & 0.150 & 0.113 & 0.178 & 0.177 \\
\hline $\mathrm{CSR}, \mathrm{k}=12$ & 0.083 & 0.115 & 0.091 & 0.138 & 0.130 & 0.117 & 0.155 & 0.116 & 0.187 & 0.182 \\
\hline CSR, $k=13$ & 0.083 & 0.115 & 0.090 & 0.138 & 0.130 & 0.119 & 0.161 & 0.121 & 0.199 & 0.187 \\
\hline$D / P$ & 0.113 & 0.163 & 0.140 & 0.177 & 0.228 & 0.116 & 0.132 & 0.115 & 0.177 & 0.152 \\
\hline$E / P$ & 0.118 & 0.178 & 0.136 & 0.186 & 0.225 & 0.098 & 0.123 & 0.115 & 0.151 & 0.172 \\
\hline $\mathrm{B} / \mathrm{M}$ & 0.112 & 0.162 & 0.140 & 0.169 & 0.225 & 0.103 & 0.121 & 0.118 & 0.165 & 0.171 \\
\hline TBL & 0.114 & 0.171 & 0.146 & 0.165 & 0.230 & 0.098 & 0.111 & 0.099 & 0.165 & 0.171 \\
\hline TMS & 0.115 & 0.175 & 0.141 & 0.176 & 0.225 & 0.097 & 0.113 & 0.101 & 0.161 & 0.172 \\
\hline DFR & 0.116 & 0.176 & 0.137 & 0.184 & 0.221 & 0.100 & 0.116 & 0.102 & 0.163 & 0.179 \\
\hline INFL & 0.117 & 0.177 & 0.138 & 0.179 & 0.222 & 0.096 & 0.113 & 0.103 & 0.159 & 0.175 \\
\hline IP & 0.115 & 0.176 & 0.138 & 0.179 & 0.221 & 0.105 & 0.114 & 0.109 & 0.157 & 0.175 \\
\hline VIX & 0.114 & 0.177 & 0.138 & 0.178 & 0.223 & 0.099 & 0.117 & 0.108 & 0.162 & 0.172 \\
\hline leverage & 0.115 & 0.177 & 0.138 & 0.182 & 0.222 & 0.097 & 0.113 & 0.102 & 0.157 & 0.173 \\
\hline uncertainty & 0.114 & 0.180 & 0.137 & 0.184 & 0.229 & 0.096 & 0.125 & 0.113 & 0.151 & 0.163 \\
\hline liquidity & 0.115 & 0.173 & 0.135 & 0.177 & 0.212 & 0.099 & 0.115 & 0.107 & 0.156 & 0.157 \\
\hline
\end{tabular}


Table A6: RMSEs for Stock Returns

\begin{tabular}{|c|c|c|c|c|c|c|c|c|c|c|}
\hline & CON & MAN & $\mathrm{HT}$ & HEL & OTH & CON & MAN & $\mathrm{HT}$ & HEL & OTH \\
\hline AR & 4.025 & 5.081 & 5.111 & 4.114 & 6.082 & 4.054 & 5.155 & 5.187 & 4.169 & 6.136 \\
\hline CSR, $k=1$ & 3.954 & 5.020 & 5.033 & 4.058 & 6.010 & 4.047 & 5.092 & 5.184 & 4.174 & 6.158 \\
\hline CSR, $k=2$ & 3.898 & 4.969 & 4.954 & 4.017 & 5.917 & 4.063 & 5.102 & 5.201 & 4.199 & 6.192 \\
\hline CSR, $k=3$ & 3.842 & 4.921 & 4.874 & 3.977 & 5.822 & 4.076 & 5.123 & 5.245 & 4.225 & 6.228 \\
\hline $\mathrm{CSR}, \mathrm{k}=4$ & 3.783 & 4.872 & 4.792 & 3.936 & 5.722 & 4.087 & 5.150 & 5.312 & 4.252 & 6.265 \\
\hline $\mathrm{CSR}, \mathrm{k}=5$ & 3.724 & 4.823 & 4.705 & 3.895 & 5.617 & 4.097 & 5.183 & 5.395 & 4.281 & 6.302 \\
\hline $\mathrm{CSR}, \mathrm{k}=6$ & 3.665 & 4.773 & 4.615 & 3.854 & 5.513 & 4.107 & 5.225 & 5.492 & 4.313 & 6.341 \\
\hline CSR, $k=7$ & 3.610 & 4.726 & 4.526 & 3.816 & 5.412 & 4.123 & 5.277 & 5.604 & 4.352 & 6.387 \\
\hline $\mathrm{CSR}, \mathrm{k}=8$ & 3.560 & 4.682 & 4.443 & 3.782 & 5.320 & 4.147 & 5.343 & 5.736 & 4.400 & 6.442 \\
\hline CSR, $k=9$ & 3.517 & 4.645 & 4.370 & 3.755 & 5.241 & 4.181 & 5.427 & 5.895 & 4.459 & 6.508 \\
\hline CSR, $k=10$ & 3.483 & 4.614 & 4.310 & 3.735 & 5.175 & 4.228 & 5.528 & 6.084 & 4.532 & 6.588 \\
\hline CSR, $k=11$ & 3.457 & 4.592 & 4.265 & 3.722 & 5.123 & 4.287 & 5.645 & 6.307 & 4.619 & 6.682 \\
\hline CSR, $k=12$ & 3.439 & 4.577 & 4.238 & 3.716 & 5.085 & 4.356 & 5.777 & 6.561 & 4.720 & 6.789 \\
\hline CSR, $k=13$ & 3.428 & 4.569 & 4.232 & 3.714 & 5.058 & 4.434 & 5.923 & 6.846 & 4.837 & 6.911 \\
\hline $\mathrm{D} / \mathrm{P}$ & 4.011 & 5.088 & 5.173 & 4.127 & 6.052 & 4.091 & 5.271 & 5.402 & 4.180 & 6.255 \\
\hline$E / P$ & 4.025 & 5.081 & 5.111 & 4.086 & 6.085 & 4.137 & 5.350 & 5.607 & 4.285 & 6.362 \\
\hline$B / M$ & 4.010 & 5.091 & 5.165 & 4.060 & 6.073 & 4.071 & 5.193 & 5.142 & 4.137 & 6.163 \\
\hline TBL & 3.968 & 5.075 & 4.979 & 4.036 & 6.003 & 4.066 & 5.187 & 5.114 & 4.172 & 6.168 \\
\hline TMS & 4.051 & 5.111 & 5.078 & 4.145 & 6.110 & 4.070 & 5.161 & 5.196 & 4.198 & 6.160 \\
\hline DFR & 4.040 & 5.078 & 5.111 & 4.118 & 6.084 & 4.205 & 5.212 & 5.579 & 4.355 & 6.420 \\
\hline INFL & 4.024 & 5.062 & 5.092 & 4.099 & 6.079 & 4.077 & 5.244 & 5.229 & 4.230 & 6.170 \\
\hline IP & 4.096 & 5.173 & 5.207 & 4.149 & 6.279 & 4.024 & 4.979 & 5.158 & 4.153 & 6.107 \\
\hline VIX & 4.058 & 5.160 & 5.176 & 4.120 & 6.162 & 4.229 & 5.261 & 5.304 & 4.237 & 6.330 \\
\hline leverage & 4.057 & 5.052 & 5.139 & 4.141 & 6.098 & 4.072 & 5.208 & 5.182 & 4.148 & 6.223 \\
\hline uncertainty & 4.012 & 5.074 & 5.116 & 4.113 & 6.066 & 4.102 & 5.282 & 5.225 & 4.220 & 6.255 \\
\hline liquidity & 4.059 & 5.064 & 5.112 & 4.112 & 6.150 & 4.086 & 5.322 & 5.567 & 4.322 & 6.247 \\
\hline
\end{tabular}


2016-17: $\quad$ Robinson Kruse, Christian Leschinski and Michael Will: Comparing Predictive Accuracy under Long Memory - With an Application to Volatility Forecasting

2016-18: $\quad$ Søren Johansen and Bent Nielsen: Tightness of M-estimators for multiple linear regression in time series

2016-19: Tim Bollerslev, Jia Li and Yuan Xue: Volume, Volatility and Public News Announcements

2016-20: $\quad$ Andrea Barletta, Paolo Santucci de Magistris and Francesco Violante: Retrieving Risk-Neutral Densities Embedded in VIX Options: a Non-Structural Approach

2016-21: Mikkel Bennedsen: Semiparametric inference on the fractal index of Gaussian and conditionally Gaussian time series data

2016-22: $\quad$ Søren Johansen and Morten Ørregaard Nielsen: The cointegrated vector autoregressive model with general deterministic terms

2016-23: $\quad$ Yunus Emre Ergemen and Carlos Vladimir Rodríguez-Caballero: A Dynamic Multi-Level Factor Model with Long-Range Dependence

2016-24: Shin Kanaya: Convergence rates of sums of a-mixing triangular arrays: with an application to non-parametric drift function

2016-25: Gustavo Fruet Dias, Marcelo Fernandes and Cristina M. Scherrer: Improving on daily measures of price discovery

2016-26: Martin M. Andreasen, Tom Engsted, Stig V. Møller and Magnus Sander: Bond Market Asymmetries across Recessions and Expansions: New Evidence on Risk Premia

2016-27: $\quad$ Kim Christensen, Ulrich Hounyo and Mark Podolskij: Testing for heteroscedasticity in jumpy and noisy high-frequency data: A resampling approach

2016-28: Kim Christensen, Roel Oomen and Roberto Renò: The Drift Burst Hypothesis

2016-29: Hossein Asgharian, Charlotte Christiansen, Rangan Gupta and Ai Jun Hou: Effects of Economic Policy Uncertainty Shocks on the Long-Run US-UK Stock Market Correlation

2016-30: $\quad$ Morten Ørregaard Nielsen and Sergei S. Shibaev: Forecasting daily political opinion polls using the fractionally cointegrated VAR model

2016-31: Carlos Vladimir Rodríguez-Caballero: Panel Data with Cross-Sectional Dependence Characterized by a Multi-Level Factor Structure

2016-32: $\quad$ Lasse Bork, Stig V. Møller and Thomas Q. Pedersen: A New Index of Housing Sentiment

2016-33: Joachim Lebovits and Mark Podolskij: Estimation of the global regularity of a multifractional Brownian motion

2017-01: Nektarios Aslanidis, Charlotte Christiansen and Andrea Cipollini: Predicting Bond Betas using Macro-Finance Variables 